\title{
Regulation of the subcellular trafficking of CD36, a major determinant of cardiac fatty acid utilization
}

Citation for published version (APA):

Glatz, J. F. C., Nabben, M., Heather, L. C., Bonen, A., \& Luiken, J. J. F. P. (2016). Regulation of the subcellular trafficking of CD36, a major determinant of cardiac fatty acid utilization. Biochimica et Biophysica Acta-Molecular and Cell Biology of Lipids, 1861(10), 1461-1471.

https://doi.org/10.1016/j.bbalip.2016.04.008

Document status and date:

Published: 01/10/2016

DOI:

10.1016/j.bbalip.2016.04.008

Document Version:

Publisher's PDF, also known as Version of record

Document license:

Taverne

Please check the document version of this publication:

- A submitted manuscript is the version of the article upon submission and before peer-review. There can be important differences between the submitted version and the official published version of record.

People interested in the research are advised to contact the author for the final version of the publication, or visit the DOI to the publisher's website.

- The final author version and the galley proof are versions of the publication after peer review.

- The final published version features the final layout of the paper including the volume, issue and page numbers.

Link to publication

\footnotetext{
General rights rights.

- You may freely distribute the URL identifying the publication in the public portal. please follow below link for the End User Agreement:

www.umlib.nl/taverne-license

Take down policy

If you believe that this document breaches copyright please contact us at:

repository@maastrichtuniversity.nl

providing details and we will investigate your claim.
}

Copyright and moral rights for the publications made accessible in the public portal are retained by the authors and/or other copyright owners and it is a condition of accessing publications that users recognise and abide by the legal requirements associated with these

- Users may download and print one copy of any publication from the public portal for the purpose of private study or research.

- You may not further distribute the material or use it for any profit-making activity or commercial gain

If the publication is distributed under the terms of Article $25 \mathrm{fa}$ of the Dutch Copyright Act, indicated by the "Taverne" license above, 


\title{
Regulation of the subcellular trafficking of CD36, a major determinant of cardiac fatty acid utilization ${ }^{2}$
}

\author{
Jan F.C. Glatz ${ }^{\text {a, }}$, Miranda Nabben ${ }^{\text {a }}$, Lisa C. Heather ${ }^{\text {b }}$, Arend Bonen ${ }^{\text {c }}$, Joost J.F.P. Luiken ${ }^{\text {a }}$ \\ a Department of Genetics E' Cell Biology, Cardiovascular Research Institute Maastricht (CARIM), Maastricht University, P.O. Box 616, 6200 MD Maastricht, the Netherlands \\ b Department of Physiology, Anatomy and Genetics, University of Oxford, Oxford, United Kingdom \\ c Department of Human Health and Nutritional Sciences, University of Guelph, Guelph, Ontario, Canada
}

\section{A R T I C L E I N F O}

\section{Article history:}

Received 11 March 2016

Received in revised form 11 April 2016

Accepted 12 April 2016

Available online 16 April 2016

\section{Keywords:}

CD36

Fatty acid uptake

Vesicle-associated membrane protein

Cardiac ischemia

Lipotoxicity

Insulin resistance

Contractile dysfunction

\begin{abstract}
A B S T R A C T
Myocardial uptake of long-chain fatty acids largely occurs by facilitated diffusion, involving primarily the membrane-associated protein CD36. Other putative fatty acid transporters, such as FABPpm, FATP1 and FATP4, also play a role, but their quantitative contribution is much smaller or their involvement is rather permissive. Besides its sarcolemmal localization, CD36 is also present in intracellular compartments (endosomes). CD36 cycles between both pools via vesicle-mediated trafficking, and the relative distribution between endosomes versus sarcolemma determines the rate of cardiac fatty acid uptake. A net translocation of CD36 to the sarcolemma is induced by various stimuli, in particular hormones like insulin and myocyte contractions, so as to allow a proper coordination of the rate of fatty acid uptake with rapid fluctuations in myocardial energy needs. Furthermore, changes in cardiac fatty acid utilization that occur in both acute and chronic cardiac disease appear to be accompanied by concomitant changes in the sarcolemmal presence of CD36. Studies in various animal and cell models suggest that interventions aimed at modulating the sarcolemmal presence or functioning of CD36 hold promise as therapy to rectify aberrant rates of fatty acid uptake in order to fight cardiac metabolic remodeling and restore proper contractile function. In this review we discuss our current knowledge about the role of CD36 in cardiac fatty acid uptake and metabolism in health and disease with focus on the regulation of the subcellular trafficking of CD36 and its selective modulation as therapeutic approach for cardiac disease. This article is part of a Special Issue entitled: Heart Lipid Metabolism edited by G.D. Lopaschuk.
\end{abstract}

(C) 2016 Elsevier B.V. All rights reserved.

\section{Introduction}

Long-chain fatty acids (for convenience referred to as 'fatty acids') constitute one of the main substrates for the heart. Under healthy conditions, $50-70 \%$ of myocardial energy production is obtained from the mitochondrial oxidation of fatty acids, the remainder being met by oxidation of carbohydrates (glucose and lactate) [1,2]. Fatty acids also are incorporated into phospholipids forming the core of biological membranes, and serve in selected signal transduction pathways to modify gene expression. On the other hand, because of their hydrophobic properties, fatty acids may exert detrimental effects and cause cellular injury $[3,4]$. As a result, the uptake and utilization of fatty acids by the heart needs to be under tight control in order to allow their unrestricted

Abbreviations: ACS, acyl-CoA synthetase; CPT-1, carnitine palmitoyltransferase-1; FABP3, heart-type fatty acid-binding protein; FABPpm, plasma membrane fatty acid-binding protein; FAT, fatty acid translocase; FATP, fatty acid transport protein; GLUT4, glucose transporter-4; SNARE, soluble $\mathrm{N}$-ethylmaleimide-sensitive factor attachment protein receptor; VAMP, vesicle-associated membrane protein.

is This article is part of a Special Issue entitled: Heart Lipid Metabolism edited by G.D. Lopaschuk.

* Corresponding author.

E-mail address: glatz@maastrichtuniversity.nl (J.F.C. Glatz). availability for mitochondrial energy production without the possible harmful effects associated with their detergent-like properties.

During the past two decades much progress has been made in understanding the specific mechanisms involved in controlling cardiac fatty acid utilization. In particular, the membrane associated protein CD36 was found to play a pivotal role in both facilitating and regulating myocardial fatty acid uptake. In this review we discuss our current knowledge about the role of $\mathrm{CD} 36$ in cardiac fatty acid utilization, focusing on both the healthy heart and the derangements that occur in cardiac disease.

\section{Mechanism of myocardial fatty acid uptake}

In blood plasma and interstitium, fatty acids are avidly bound by albumin $(68 \mathrm{kDa})$ or are present as triacylglycerols in lipoproteins (chylomicrons, very low density lipoproteins) from which they are released after hydrolysis by lipoprotein lipases located at the surface of the capillaries. Intracellularly, fatty acids are bound by cytoplasmic heart-type fatty acid-binding protein (H-FABP, also designated as FABP3; $15 \mathrm{kDa}$ ) which acts as the intracellular counterpart of albumin [5]. Albumin and H-FABP each bind fatty acids with such high affinities that virtually all of the fatty acids present in the aqueous compartment 
are protein-bound. Thus, in plasma and interstitium the total fatty acid concentration is $100-400 \mu \mathrm{M}$ while the concentration of non-protein bound ('free') fatty acids is several orders of magnitude lower and amounts to only 1-10 nM [6,7]. Similarly, for cardiomyocytes it has been estimated that in the (soluble) cytoplasm the total fatty acid concentration is up to $50 \mu \mathrm{M}$ (depending on the metabolic state of the cell) while the non-protein bound fatty acid concentration is only 1-5 nM $[8,9]$. As a result, albumin and H-FABP each provide a buffer for fatty acids, whereby each fatty acid molecule that is metabolized or undergoes transmembrane transport to another compartment is immediately replenished by the release of another fatty acid molecule from the protein binding site. It should be emphasized that the abundance of albumin in both plasma (approximately $600 \mu \mathrm{M}$ ) and interstitium $(300 \mu \mathrm{M})$ and that of H-FABP in the soluble cytoplasm (150-300 $\mu \mathrm{M}$ in cardiomyocytes) presents with a total buffering capacity that markedly exceeds the total fatty acid concentration in each compartment. This ensures that the non-protein bound fatty acid concentration remains low, even under mild pathological conditions (e.g., mild ischemia), so as to keep fatty acids from exerting potential detrimental effects [9].

The uptake of fatty acids into cardiomyocytes involves their physical transport across the plasma membrane (sarcolemma). Following two decades of considerable debate on the molecular mechanism by which fatty acids traverse the sarcolemma, in particular with respect to the rate-limiting step(s) and the membrane-associated proteins involved (for review see [10-12]), there is now consensus by and large on the myocardial fatty acid uptake process. For this, distinction should be made among three separate steps that together comprise the transsarcolemmal uptake (Fig. 1).

(A) Adsorption: entry of the fatty acid into the outer leaflet of the lipid bilayer, whereby the hydrocarbon chain intercalates between the chains of the phospholipid and the carboxyl group localizes at the aqueous interface. The prevalent view is that membrane-associated proteins facilitate the sequestering of fatty acids in the membrane and thus act as fatty acid acceptor.

(B) 'Flip-flop': transfer of the fatty acid from the outer to the inner leaflet, whereby the polar carboxyl group moves through the bilayer interior and re-positions at the opposite interface.

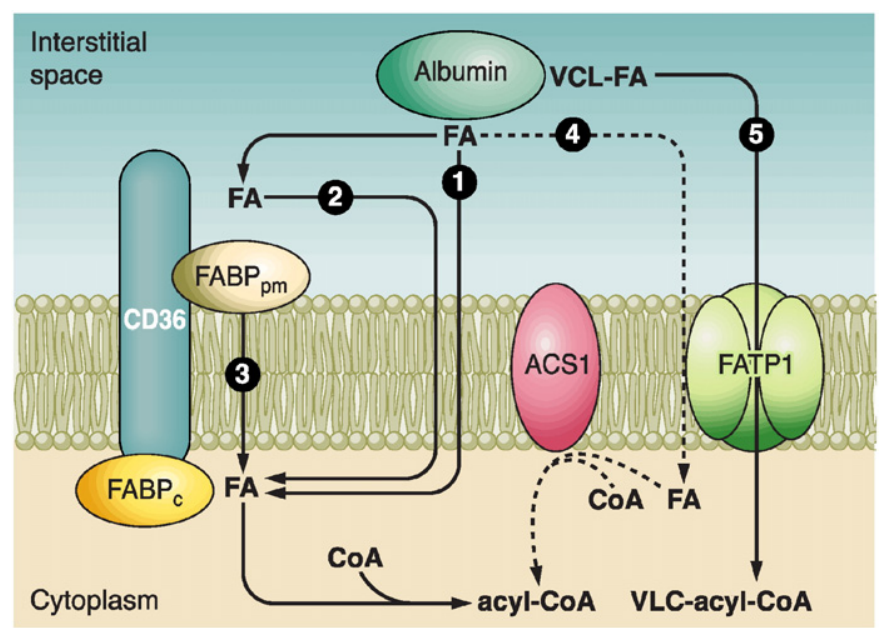

Fig. 1. Putative molecular mechanism(s) for the cellular uptake of long-chain fatty acids (FA) and of very-long-chain fatty acids (VLC-FA). In view of their hydrophobic nature, fatty acids could dissociate from their albumin binding sites and cross the plasma membrane by simple diffusion (route 1 , uptake by passive diffusion). Alternatively, the membrane-associated proteins FABPpm, CD36, and FATP, either separately or together, may facilitate the transport of fatty acids across the phospholipid bilayer (routes $2-5$, uptake by facilitated diffusion). See text for detailed description of the various routes. Reproduced from [11], with permission.
Biophysical studies have shown that 'flip-flop' of fatty acids in a phospholipid bilayer is very fast for virtually all fatty acid types [13]. Therefore, the possible role for membrane-associated proteins in this step most likely is restricted to determining the membrane domain where 'flip-flop' takes place, rather than the rate of fatty acid translocation from the outer to the inner leaflet.

(C) Desorption: movement of the fatty acid into the intracellular aqueous phase and hydration of the fatty acid. This step appears rate-limiting for the entire transmembrane transport and is strongly dependent on chain length and degree of unsaturation of the fatty acid $[14,15]$. There is some evidence that transmembrane proteins, in particular CD36 [16], provide a docking site for cytoplasmic H-FABP or for enzymes that act on fatty acids such as acyl-CoA synthetase, and in this way facilitate the desorption step.

The main membrane-associated proteins involved in myocardial fatty acid uptake include $(i)$ the transmembrane protein CD36 (also referred to as putative fatty acid translocase, FAT) of $88 \mathrm{kDa}$ that was first identified in rat adipocytes by Abumrad and colleagues [17], (ii) the peripheral membrane protein FABPpm of 40-43 kDa identified by Stremmel [18], and (iii) two members of the family of fatty acid-transport proteins (FATP), i.e., FATP1 and FATP4, first described by Schaffer and Lodish $[19,20]$. As illustrated in Fig. 1, CD36 and FABPpm, either alone or in concert [21], are envisaged to act as an acceptor for fatty acids to increase their concentration at the cell surface and thus enhance the number of fatty acid diffusion events (route 2). Being a transmembrane protein, CD36 itself may also facilitate the transport of fatty acids across the phospholipid bilayer (route 3 , uptake by facilitated diffusion). Once at the inner side of the cell membrane, fatty acids are bound by cytoplasmic $\mathrm{H}$-FABP before entering metabolic or signaling pathways. The direction and overall rate of fatty acid uptake is determined by the transsarcolemmal gradient of fatty acids [2,15]. Additionally, a minority of fatty acids are thought to be transported by FATP1 and rapidly activated by plasma membrane acyl-CoA synthetase (ACS1) to form acyl-CoA esters (route 4). Specific fatty acid types, i.e., very long-chain fatty acids (VLC-FA, chain length $>22$ carbon atoms), are preferentially transported across the sarcolemma by FATP1 or FATP4 and by action of the synthetase activity of these FATPs immediately converted into VLC-acyl-CoA esters (route 5, uptake by vectorial acylation or metabolic trapping).

Quantitative studies have revealed that the majority of fatty acids are taken up into cardiomyocytes by facilitated diffusion with CD36 being the main membrane-associated protein involved. In studies on mice with a targeted deletion of CD36 it has been estimated that the contribution of CD36-mediated fatty acid uptake to total fatty acid uptake is about 70\% [22]. Passive diffusional uptake of fatty acids is not excluded but under normal conditions will contribute only marginally to the overall rate of fatty acid uptake [23,24].

Following their uptake into cardiomyocytes, fatty acids are first activated into their acyl-CoA esters and then either undergo mitochondrial $\beta$-oxidation to produce ATP, are used for phospholipid synthesis, or are incorporated into triacylglycerols for storage. The intracellular fate of fatty acids is dependent on the need for metabolic energy (in particular the rate of contraction), and on the hormonal milieu (e.g., insulin).

\section{Protein structure of CD36}

CD36 is an integral membrane glycoprotein of a single chain of 472 amino acids ( $53 \mathrm{kDa}$ ) that has a hairpin membrane topology with two transmembrane spanning regions, with both the $\mathrm{NH}_{2}$ and $\mathrm{COOH}$ termini as short segments in the cellular cytoplasm (Fig. 2) (reviewed in [25-27]). The $\mathrm{NH}_{2}$-terminal hydrophobic domain appears to serve as a transmembrane anchor. The protein is heavily glycosylated and has $10 \mathrm{~N}$-linked glycosylation sites situated in the large extracellular loop 


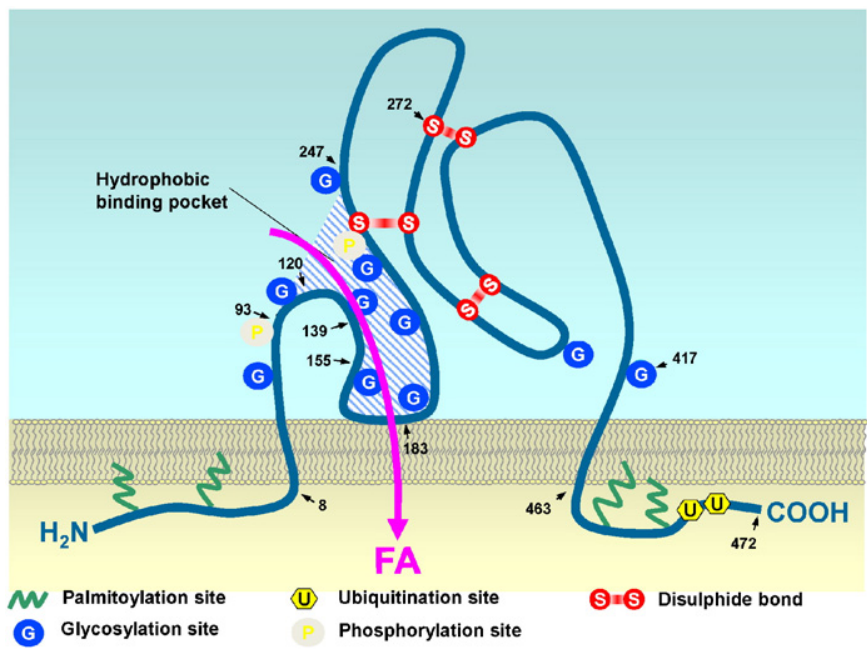

Fig. 2. Schematic presentation of the proposed structure and membrane topology of CD36. The large extracellular loop has 10 putative $N$-linked glycosylation sites and two phosphorylation sites. Disulfide bonds between extracellular cysteines are envisioned between amino acid residues 243-311, 272-333, and 313-323. The small cytoplasmic tails contain the $\mathrm{NH}_{2}$ and $\mathrm{COOH}$ termini and each are palmitoylated, most likely to anchor the protein in the membrane. In addition, the $\mathrm{COOH}$ terminus contains two ubiquitination sites. The shaded area designates a hydrophobic pocket comprised by amino acid residues 93-183 that likely is involved in ligand binding. The region formed by residues 93-120 was identified as the thrombospondin binding site, that by residues $120-155$ was mapped for oxidized LDL, while residues 139-183 form a multiligand binding site. Arrowheads and numbers indicate the approximate positions of amino acid residues. Reproduced from [11], with permission.

[28]. This extensive glycosylation increases the apparent mass of CD36 from 53 to $88 \mathrm{kDa}$. The protein also has two phosphorylation sites and three external disulfide bridges, and contains four palmitoylation sites, two each at the extreme $\mathrm{NH}_{2}$ and $\mathrm{COOH}$ termini [29]. Finally, the $\mathrm{COOH}$ terminal domain of CD36 contains two ubiquitination sites (Fig. 2).

CD36 was first known as leukocyte cluster-of-differentiation antigen or glycoprotein IV, and now is recognized as a ubiquitously expressed class B scavenger receptor protein with multiple functions, particularly the binding of thrombospondin, oxidized low-density lipoprotein (LDL), and anionic phospholipids, and its action as gustatory lipid sensor [30,31]. The fatty acid binding property of CD36 was disclosed in 1993 by Abumrad and co-workers when they found that a protein they had initially designated putative fatty acid translocase (FAT) appeared to be identical to CD36 [17]. Therefore, in its function as a facilitator of cellular fatty acid uptake, CD36 often is referred to as FAT/CD36 and, for convenience, also as 'fatty acid transporter' although the latter strictly is incorrect.

The complexity of the $\mathrm{CD} 36$ protein with its many post-translational modifications has hampered the elucidation of its three-dimensional structure. However, recently the crystal structure of LIMP-2, a member of the CD36 superfamily of scavenger receptors, was determined and used to infer, by homology modelling, the structure of CD36 [32]. These studies gave further evidence for the existence of a large cavity that traverses the entire length of the molecule. This cavity serves as a tunnel through which lipids are delivered to the outer leaflet of the plasma membrane [32]. This latter finding would account for the selective involvement of CD36 in cellular uptake of lipid species.

\section{Control of myocardial fatty acid uptake}

Rapid fluctuations in energy needs of the heart require a coordinated adaptation of the rate of substrate uptake. At a given point in time the myocardial energy content (ATP and creatine phosphate) is sufficient to allow contractile activity to continue for up to a minute only, and endogenous substrate stores (glycogen and triacylglycerols) are limited.
Thus, regulating substrate uptake allows the heart to fine tune energy demand with fuel supply. In addition, it would be undesirable to have fatty acids enter cardiomyocytes without control driven solely by the plasma lipid concentration, as this may cause lipid overload and its resulting lipotoxic effects $[3,4]$. Insight into the regulation of myocardial fatty acid uptake was markedly enhanced when we discovered that fatty acid uptake occurs by a mechanism that closely resembles that of cellular glucose uptake [33]. Specifically, in response to an increase in contraction or to an external trigger such as insulin, CD36 translocates from an intracellular store (endosomes) to the sarcolemma to facilitate fatty acid uptake, just as these same stimuli recruit glucose transporter GLUT4 to the sarcolemma to increase cellular glucose uptake (Fig. 3). Furthermore, for both CD36 and GLUT4 recruitment the effects of increased contraction and of insulin are additive. Importantly, the intracellular fate of the incoming fatty acids, i.e., mitochondrial oxidation or storage into triacylglycerols, is not influenced by CD36 but determined by the metabolic demands and the hormonal milieu [34,35]. Although in heart and skeletal muscle, the main fatty acid transporter that functions by this mechanism is CD36, translocation of FATP1 and FATP4 has also been described to occur in skeletal muscle [36] but not cardiac muscle [37], suggesting that subcellular recycling of substrate transporters is a common mechanism to regulate substrate uptake.

Changes in the sarcolemmal presence of CD36 appear to directly correlate with changes in myocardial fatty acid uptake rate. Importantly, acute changes in fatty acid uptake can be realized by redistribution of CD36 between the endosomal storage pool and the sarcolemma and do not need long term adaptations in de novo protein synthesis or breakdown of CD36. In contrast, chronic changes in fatty acid uptake are often accompanied by changes in the total CD36 pool. For instance, while insulin acutely induces the subcellular translocation of CD36 to the sarcolemma, upon longer exposure to insulin it also increases the expression of total CD36 protein [38]. Chronic lipid oversupply of the heart induces a net translocation of CD36 to the sarcolemma concomitant with a net translocation of GLUT4 to intracellular storage pools without changes in cellular protein contents of either substrate transporter. These observations suggest that despite a high degree of similarity between the subcellular recycling of CD36 and GLUT4, differences exist in the molecular mechanisms underlying these translocations (to be discussed below).

The disclosure of a role for membrane-associated proteins, particularly CD36, in the regulation of myocardial fatty acid uptake, has added a new site of control to the overall rate of myocardial fatty acid utilization. In the heart (as well as in liver and skeletal muscle) carnitine palmitoyl-transferase-1 (CPT-1) is well-established to acutely regulate fatty acid $\beta$-oxidation via its allosteric inhibitor malonyl-CoA. The enzymatic activity of CPT-1 is generally proposed to be the overall ratelimiting step in cellular fatty acid utilization $[2,39]$. Distinction should be made between three isoforms of CPT-1, i.e., CPT-1 A which occurs in liver, CPT-1B in heart and skeletal muscle, and CPT-1C in brain [40]. Recent work has questioned the overall rate-limiting role for CPT-1B in heart. First, the concentration of malonyl-CoA in the heart has been estimated to be $1-10 \mu \mathrm{mol} / \mathrm{L}[41,42]$, which greatly exceeds the half maximal inhibitory concentration for CPT-1B to malonyl-CoA $(0.02 \mu \mathrm{mol} / \mathrm{L})$. Hence, $\beta$-oxidation would, theoretically, be permanently blocked if CPT-1B is rate-limiting for $\beta$-oxidation [43]. Second, in perfused hearts from $\mathrm{db} / \mathrm{db}$ mice, a genetic model of obesity and type $2 \mathrm{di}$ abetes in which cardiac fatty acid oxidation is markedly increased [44], a 4-fold increase in fatty acid oxidation occurred independent of changes in CPT-1B activity [45]. These observations suggest that CPT-1B activity may not be rate-limiting for cardiac $\beta$-oxidation. Third, in CD36-null mice, in which CPT-1B protein expression is not altered, fatty acid oxidation is impaired, particularly during a metabolic challenge [35]. This indicates that sarcolemmal fatty acid transporters, notably CD36, are major determinants of the rate of fatty acid oxidation. Finally, partial inhibition of CPT-1B activity in vivo in rats using etomoxir, a specific inhibitor of CPT-1, resulted in a $44 \%$ reduced cardiac CPT-1B activity, 


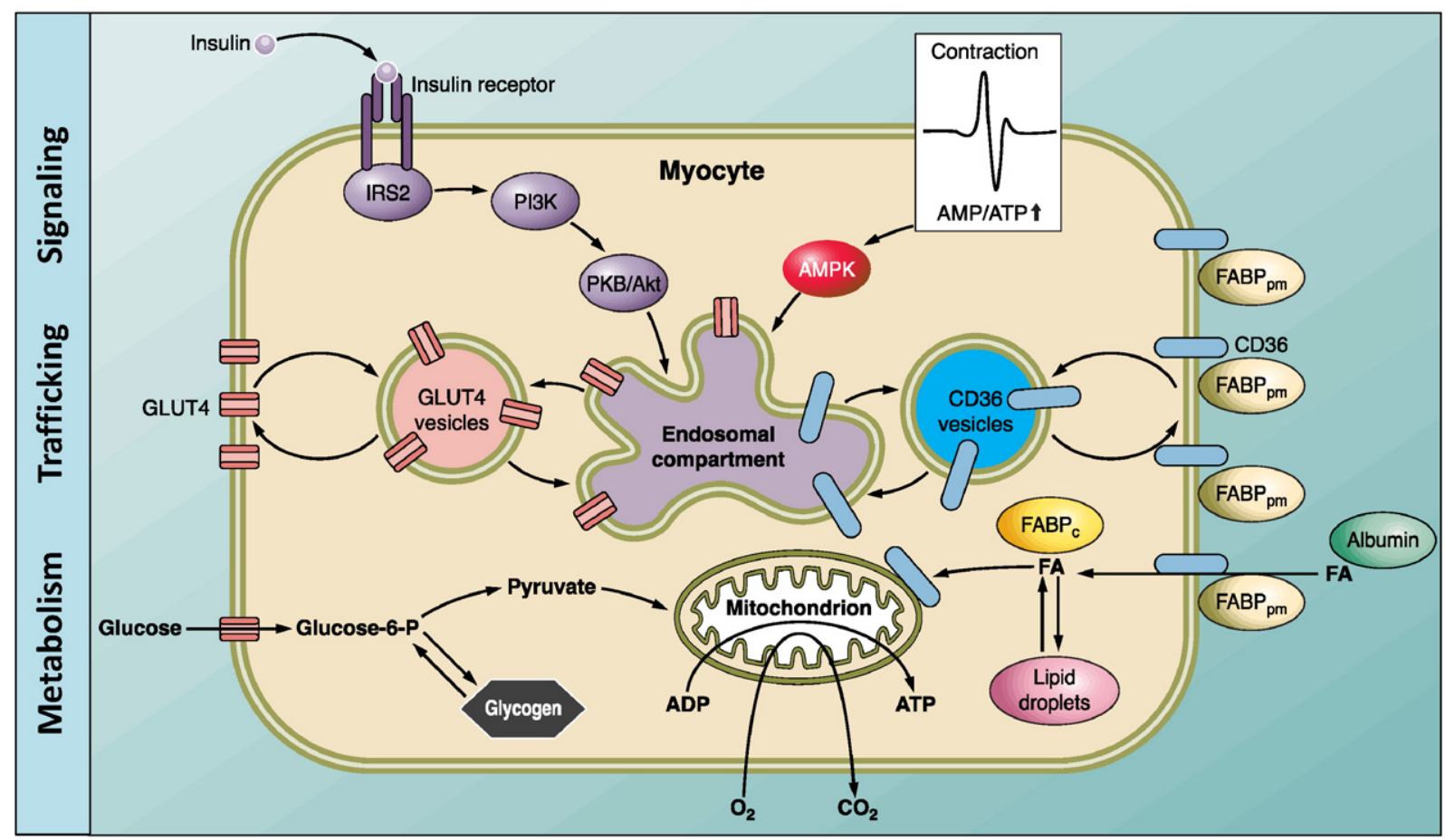

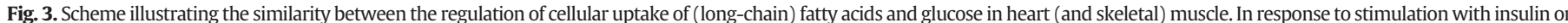

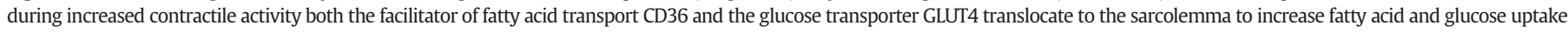

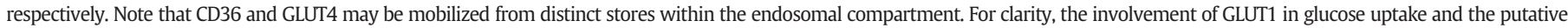
recycling of other membrane-associated fatty acid-binding proteins (notably FABPpm, FATP1 and FATP4) are not shown. FA, long-chain fatty acid. Reproduced from [11], with permission.

but failed to alter the rates of cardiac fatty acid uptake and/or oxidation [46]. Together, these data suggest that CPT-1B does not act as a major rate-controlling site in total cardiac fatty acid flux, and we propose that cellular fatty acid uptake (trans-sarcolemmal transport) is a primary site for fatty acid flux regulation.

\section{Mechanism and regulation of subcellular CD36 recycling}

Vesicle-mediated transport is needed to bring newly synthesized or recycling proteins to the membrane in which they function or to internalize proteins for either intracellular degradation or storage (i.e., recycling). Steps of such transport need to be unidirectional and extremely specific to ensure that vesicles containing membrane proteins destined for the plasma membrane do not fuse randomly with membranes from other organelles. Each mammalian cell type contains a specific set of trafficking proteins, referred to as the trafficking machinery, to provide both this unidirectionality of intracellular transport and the proper sorting mechanisms.

The trafficking machinery dedicated to the recycling of CD36 in cardiac myocytes is currently being unraveled. Focus in these studies is on its relation to the trafficking of GLUT4, because knowledge of both the similarities and differences between the recycling of CD36 and that of GLUT4 may enable modulation of cardiac substrate preference as therapy for cardiac metabolic disease (to be discussed below). It should be noted that the trafficking machinery involved in GLUT4 recycling [e.g. 47,48] has gained much more attention than that of CD36 [11]. The isolation of GLUT4 vesicles from adipocytes revealed that at least 48 distinct proteins are involved in the regulation and specificity of vesicular GLUT4 transport [49]. CD36 vesicles have been isolated from rat heart [50], but have not been extensively studied with a proteomic approach.

In general, subcellular vesicular protein transport can be differentiated into three components; vesicle fission at the donor compartment, subcellular vesicle transport, and vesicle fusion at the acceptor membrane (Fig. 4).

(1) Vesicle fission: At the donor compartment, the membranes will be curved into a bud that subsequently will excise. This process is dependent on bilayer destabilizing proteins, coat proteins (also named scaffolding proteins), Ras-related Rab GTP-binding proteins (Rab-GTPases) and a number of adaptor proteins forming a so-called fission complex. To initiate vesicle fission, coat proteins are recruited to membrane spots where cargo is concentrated by adaptor proteins. This process is regulated by Rab-GTPases which cycle between GTP-bound (active) and GDP-bound (inactive) conformations thereby acting as molecular switches. Coat proteins then form a 'bulb' in the membrane and, with the aid of scission proteins, start budding of a vesicle. Once the vesicle is formed and detached from the organelle, the coat proteins are released.

(2) Vesicle transport: Upon binding of a motor protein the newly formed transport vesicles move along one of the cytoskeletal networks to their designated target membrane. This process is also regulated by Rab-GTPases.

(3) Vesicle fusion: Tethering proteins trap the transport vesicle below the cell surface. The interaction of a specific subset of vesicle-associated soluble $N$-ethylmaleimide-sensitive factor attachment protein receptors ( $\mathrm{v}$-SNAREs) and their cognate target-membrane associated SNAREs (t-SNAREs), forming a so-called SNARE complex, brings the vesicle to such a close proximity to the sarcolemma that the water barrier can be overridden and fusion of the two membranes can occur. After fusion, the SNARE complex disintegrates.

Below we will discuss our current knowledge of these three steps, focussing on CD36 translocation. 


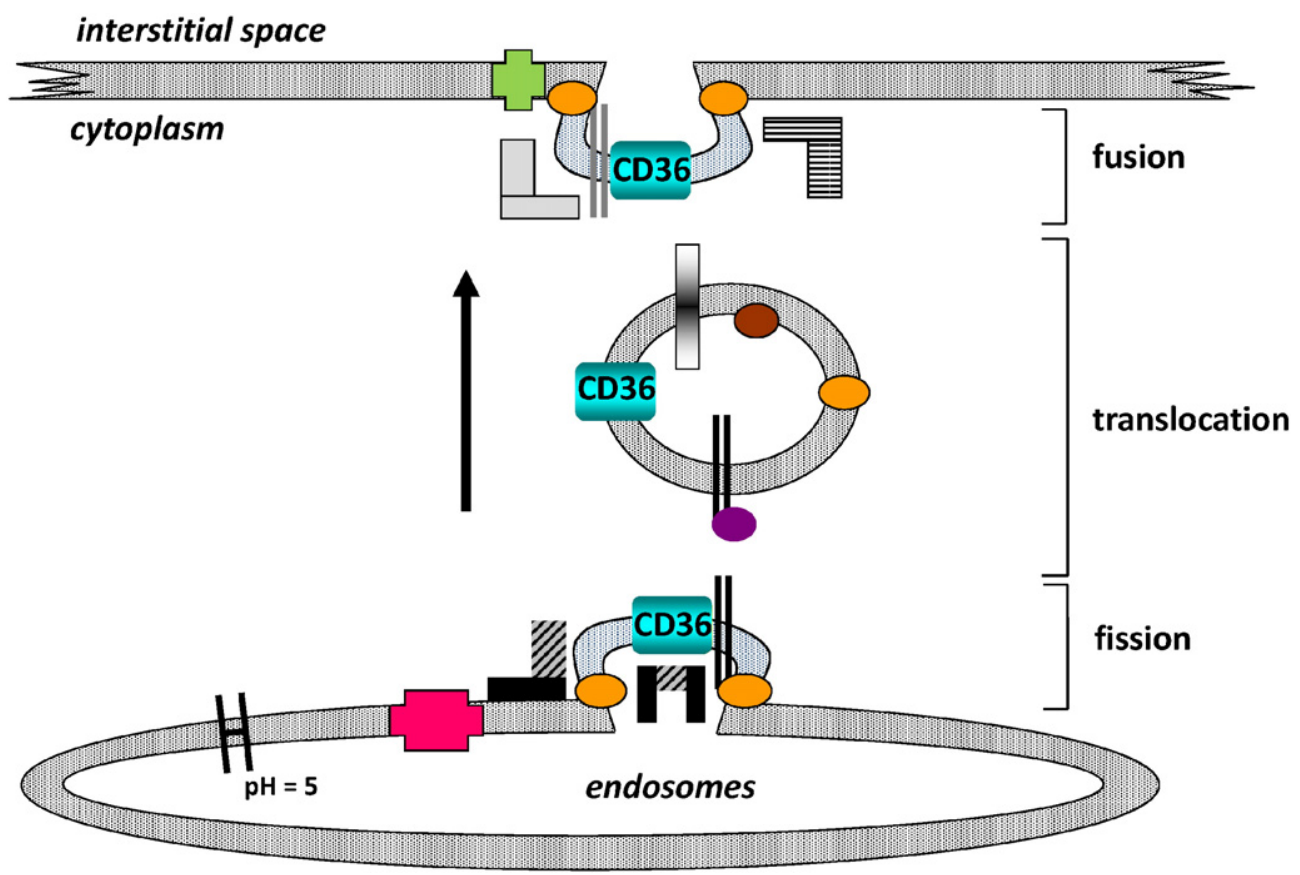

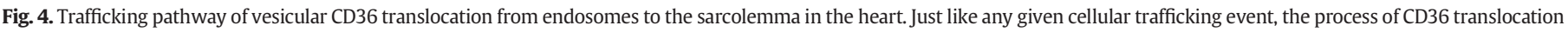

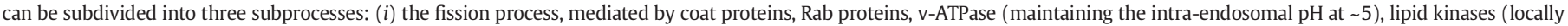

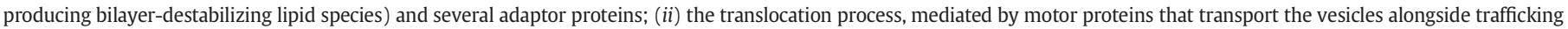

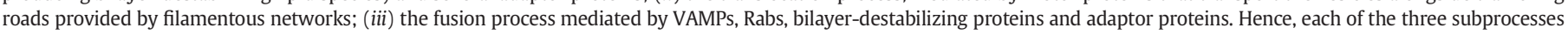

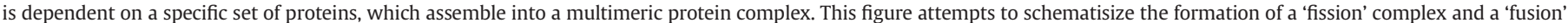

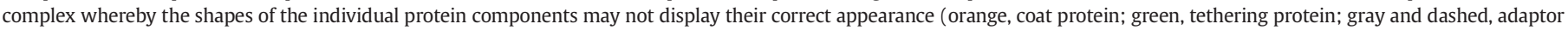
proteins; red, lipid kinase).

Ad (1) Well-known classes of coat proteins are clathrins, coat protein complex (COP) and caveolins. These proteins share the same mechanism of initiation of budding, but appear involved in different trafficking processes [51]. Studies performed in cardiomyocytes show that COP proteins and/or clathrin function in both stimulus-induced glucose and fatty acid uptake [52]. Although there is evidence that caveolin-1 is involved in CD36 and GLUT4 translocation in non-muscle cells, caveolin-3 (the muscle-specific isoform of caveolin) most likely does not play a role in translocation of both transporters in (cardiac) muscle because regulation of cardiac fatty acid uptake was not altered in caveolin-3 null mice [53].

Preliminary studies have elucidated that formation of CD36 vesicles is also dependent on the endosomal $\mathrm{pH}$, which is regulated by vacuolartype $\mathrm{H}^{+}$-ATPase (v-ATPase). Treatment of cardiomyocytes with the specific v-ATPase inhibitor bafilomycin-A or the proton ionophore monensin rapidly induced the translocation of CD36, not GLUT4, to the sarcolemma, indicating that a low endosomal $\mathrm{pH}$ is essential for intracellular retention of CD36 [52]. Interestingly, while basal GLUT4 translocation is not dependent on v-ATPase function (i.e., low endosomal $\mathrm{pH}$ ), insulin-induced GLUT4 translocation is impaired when v-ATPase is inhibited [52]. Hence, CD36 and GLUT4 are differentially regulated by endosomal $\mathrm{pH}$.

Rab proteins form a family of small GTPases ( $>70$ members). Each member provides specificity and unidirectionality to the trafficking process of its involvement. While specific Rab members have been identified on their involvement in GLUT4 trafficking [54], little is known about their involvement in CD36 translocation. Rab8a appears to be involved in stimulus-induced CD36 translocation [55] whereas Rab11 mediates CD36 internalization [56]. Furthermore, the Rab GTPase-activating protein AS160 inhibits stimulus-induced CD36 translocation, likely by keeping Rab8a in its inactive form [55]. Notably, both Rabs and AS160 have similar functions in GLUT4 translocation. The only protein involved in Rab-dependent trafficking that so far has been found to discriminate between CD36 and GLUT4 trafficking is the Rab11 effector protein Rip11, by assisting in Rab11-mediated CD36 internalization [56].

Ad (2) Similar to other trafficking processes, CD36 translocation is likely to be dependent on filamentous networks, providing the intracellular 'roads' for the transport vesicles. CD36 trafficking is not affected by inhibitors of actin polymerization/de-polymerization cycles or by microtubule destabilizers [52]. Hence, the filamentous networks involved in CD36 translocation await identification.

Ad (3) Specificity of protein transport is believed to be achieved to a large extent by interaction between v-SNAREs and t-SNAREs during vesicle fusion with the target membrane. This process is highly selective as a v-SNARE interacts with only a specific subset of t-SNAREs to form a SNARE complex that initiates fusion. For instance, at the sarcolemma, upon insulin stimulation the v-SNARE vesicle-associated membrane protein-2 (VAMP2) interacts with the t-SNAREs syntaxin4 and SNAP23 to initiate fusion of GLUT4-containing vesicles [57]. Members of the VAMP protein family have been found to be differentially involved in GLUT4 and CD36 trafficking in cardiac myocytes [58,59]. Three VAMPs were demonstrated to be required for both CD36 and GLUT4 translocation, either specifically in insulin-induced translocation (VAMP2, VAMP5) or in contraction-induced translocation (VAMP3). In addition, VAMP7 was found to be specifically involved in GLUT4 traffic (mediating basal GLUT4 retention) and VAMP4 specifically in CD36 traffic (both insulin- and contraction-induced translocation) [58]. These differences indicate the possibility to use VAMPs to discriminate between CD36 and GLUT4 translocation (to be discussed below).

Various other proteins known to be involved in vesicular trafficking may also participate in CD36 and/or GLUT4 recycling and bring specificity to either process. For example, the accessory protein Munc18c, a member of the Sec1p-like/Munc18 family which functions in the transition of 
syntaxins (t-SNAREs) into their open and closed states [60], forms a complex with syntaxin 4 and was observed to be essential - but not rate-limiting - for both cardiac CD36 and GLUT4 translocation [61].

Taken together, insight into the molecular mechanisms that regulate the trafficking of CD36 to and from the sarcolemma, both in the basal state and upon stimulation by hormones or muscular contraction, are only beginning to be disclosed. However, the knowledge obtained so far clearly indicates that specificity of CD36 trafficking, especially in relation to that of GLUT4, is provided by the involvement of selected proteins from the cellular trafficking machinery.

\section{CD36 and changes in cardiac substrate metabolism during ischemia and reperfusion}

Given the role of CD36 in fatty acid utilization by the healthy heart, it is to be expected that acute or chronic changes in cardiac fatty acid metabolism that occur in disease states will also be accompanied by concomitant adaptations in the subcellular localization and/or expression of CD36. Conversely, changes in CD36 content, localization or functioning, potentially caused by external effectors, will likely have an impact on myocardial fatty acid utilization. Examples of both alterations have been described, and suggest that CD36 may be exploited as therapeutic target.

During ischemia, cardiac metabolism must rapidly adapt to the limited oxygen supply in order to optimize anaerobic ATP generation and ensure cell survival. Therefore, ischemia upregulates glucose uptake and glycogenolysis, while mitochondrial fatty acid oxidation is downregulated $[62,63]$. These acute metabolic changes are known to be facilitated by concomitant rapid changes in metabolic enzyme activities, i.e., an increase in activity of glycolytic enzymes and a decrease in that of mitochondrial enzymes. However, adaptation to ischemia should also encompass a decrease in myocardial fatty acid uptake so as to match the lower fatty acid utilization rate in the face of an elevation of the plasma fatty acid concentration, to prevent intracellular lipid accumulation. In a recent study with isolated perfused rat hearts we observed that during $30 \mathrm{~min}$ of low-flow ischemia, the sarcolemmal CD36 protein content decreased significantly due to movement of CD36 from the sarcolemma to the endosomes, with a concomitant decrease in the rate of palmitate oxidation (Fig. 5) [64]. This was accompanied by an opposite movement of the glucose transporter GLUT4, i.e., away from the endosomal stores to the sarcolemma, which coincides with an increase in glucose uptake (Fig. 5). Interestingly, during subsequent $30 \mathrm{~min}$ of reperfusion the fatty acid oxidation and glucose utilization rates each were restored to their preischemic level, however the subcellular localization of CD36 and that of GLUT4 did not change. Rather, the decreased sarcolemmal CD36 was associated with depletion of cellular triacylglycerols, while the increased sarcolemmal GLUT4 facilitated the repletion of glycogen (Fig. 5) [64]. These data clearly show that changes in the subcellular recycling of CD36 contribute to the acute cardiac metabolic remodeling that occurs during ischemia and reperfusion, thereby preventing possible lipid accumulation and its associated detrimental effects.

In addition to acute decreases in CD36 sarcolemmal content during ischemia and reperfusion, studies have also investigated the longer term changes in fatty acid uptake capacity in chronic ischemic heart disease. In rodent models of heart failure, total CD36 protein content was decreased in line with myocardial fatty acid utilization, and this decrease correlated positively with in vivo cardiac function [65]. In left ventricular biopsies obtained from patients with aortic stenosis, total CD36 protein content decreased proportional to the degree of cardiac hypertrophy in these patients, and was accompanied by an increase in GLUT4 protein levels [66]. Thus, in both acute and chronic ischemia sarcolemmal CD36 protein levels are modulated, but via different mechanisms, and are an integral part of the metabolic remodeling in cardiac disease.

\section{CD36 and lipid-oversupply induced cardiac insulin resistance and contractile dysfunction}

In obesity the plasma fatty acid concentration is commonly elevated and has previously been suggested to represent the link between obesity, insulin resistance, and the development of contractile dysfunction [67]. An increase in fatty acid delivery to the heart can trigger insulin resistance, as was shown in transgenic mice with a tissue-specific overexpression of lipoprotein lipase, the rate controlling enzyme involved in hydrolysis of triacylglycerols [68]. The insulin resistant state is usually associated with an accumulation of intramuscular triacylglycerols. However, this intracellular rise in triacylglycerols by itself is not harmful, but is an indicator of elevated levels of lipid intermediates such as diacylglycerols, ceramides and long-chain acyl-CoAs [69]. These lipid intermediates interfere in the insulin signaling cascade by activating a ser/thr phosphorylation cascade involving protein kinase $C-\theta$ (thereby inhibiting insulin receptor substrate-1/2) and by directly inhibiting Akt/protein kinase B activation [69]. This leads to an insulin resistant state, whereby the heart is unable to properly respond to plasma insulin to increase (GLUT4-mediated) glucose uptake.

Evidence is accumulating that CD36 plays a key role in the development of insulin resistance due to lipid overload. A decade ago we showed that in hearts from high fat fed rats and from type 2 diabetic rodent models ( $d b / d b$ mice and obese Zucker rats), the increased rates of fatty acid esterification and lipid accumulation positively correlated with an increased sarcolemmal presence of CD36 [45, 70-72]. Moreover, blocking CD36-mediated fatty acid uptake in isolated cardiac myocytes from these models, using the specific inhibitor sulfo- $\mathrm{N}$-succinimidyl-oleate (SSO), lowered the augmented rate of fatty acid esterification [70,71]. A similar effect was reported for ablation of CD36 in a model of lipotoxic cardiomyopathy [73]. These data indicate that the upregulation of CD36 at the sarcolemma in the insulin resistant heart is a key factor contributing to the intramyocellular accumulation of lipids.

More recently we performed a detailed time-course study in rats subjected to a high fat diet to examine the chronological changes in circulating substrates and insulin, and in sarcolemmal substrate transporters and transport, intramyocellular lipids, and mitochondrial fatty acid oxidation in skeletal muscle [74]. In general, (patho)physiological changes in substrate metabolism in skeletal muscle appear to be similar to those in cardiac muscle [11]. It was found that within 2-3 days, diet-induced increases occurred in insulin, sarcolemmal CD36 (not FABPpm nor FATP1), fatty acid uptake and intramyocellular triacylglycerols, diacylglycerols and ceramide, independent of enzymatic changes or a change in muscle fatty acid oxidation. Diet-induced increases in mitochondria and mitochondrial fatty acid oxidation and impairments in insulin-stimulated GLUT4 translocation and glucose transport occurred much later, i.e., after 21 days (Fig. 6) [74]. These data have revealed that upon high fat feeding, changes in lipid metabolism precede the onset of muscle insulin resistance by $16-19$ days. This appreciable delay in the onset of insulin resistance suggests that additional mechanisms besides the intramyocellular accumulation of lipids contribute to this pathology.

Taken together, on the basis of the findings described above, high fat diet-induced cardiac insulin resistance is suggested to be the result of the following steps: in response to the increased delivery of fatty acids to the heart there is a very rapid (2-3 days) increase in sarcolemmal CD36 and fatty acid uptake, which accounts for fatty acid becoming the main metabolic substrate for energy production and for very rapid intramyocellular accumulations of triacylglycerols, diacylglycerols, and ceramides. These latter fatty acid metabolites inhibit insulin signaling and impair the translocation of GLUT4 from endosomes to the sarcolemma, resulting in lowered glucose uptake and a decreased incorporation of glucose into glycogen. At that stage, the heart has become insulin resistant. 
A
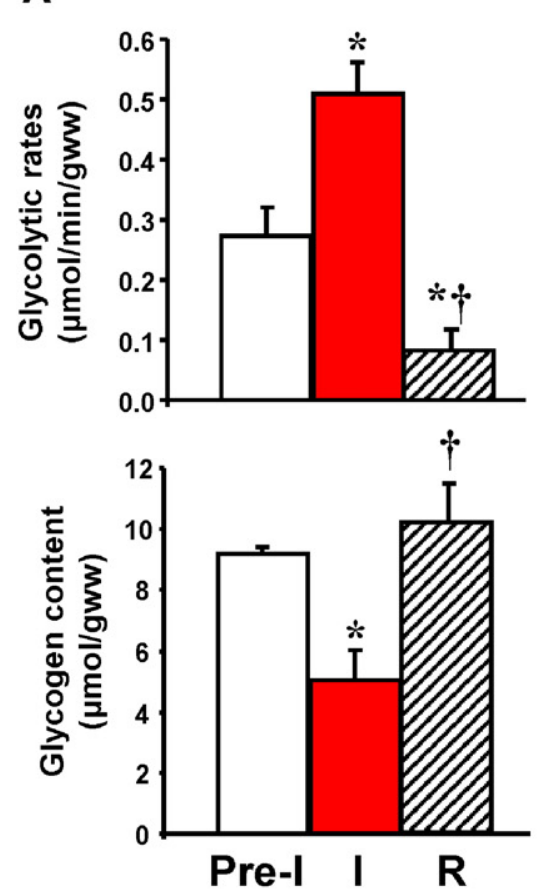

B
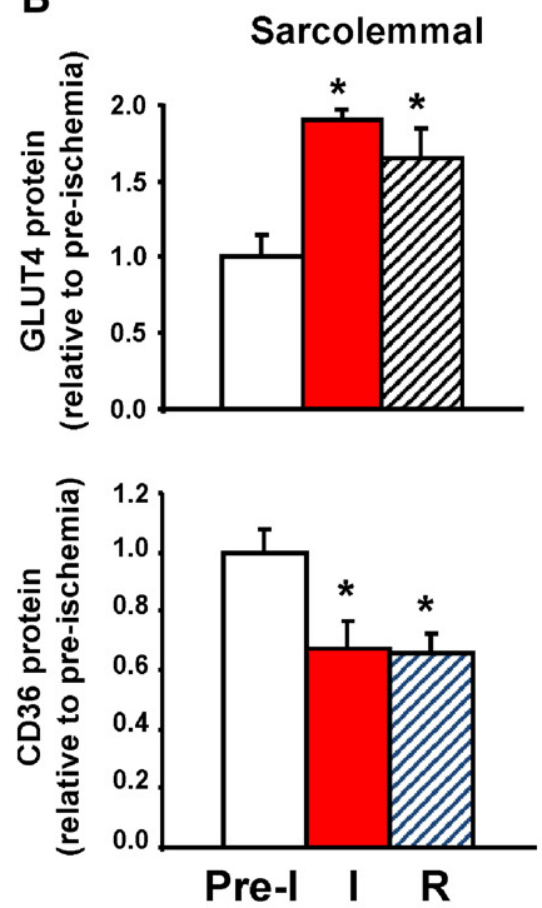

\section{Ischemia $\bigotimes$ Reperfusion}
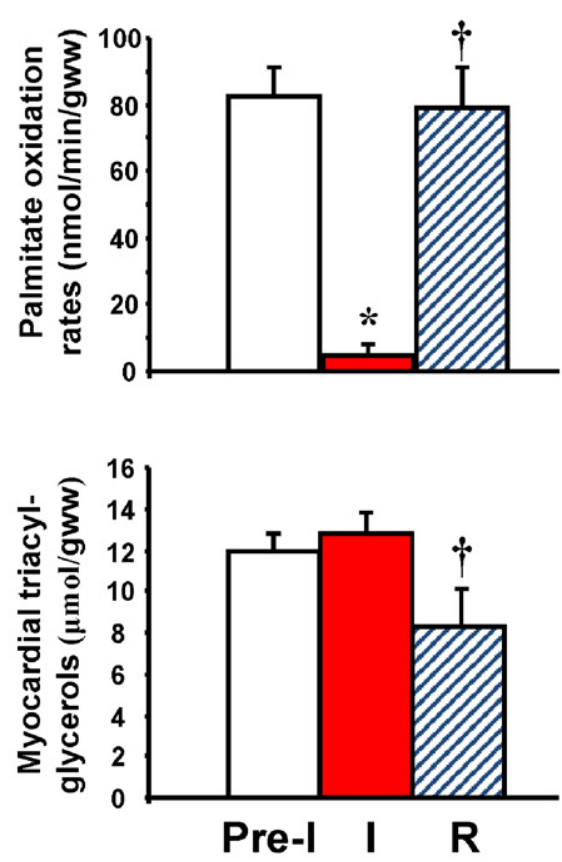

Endosomal
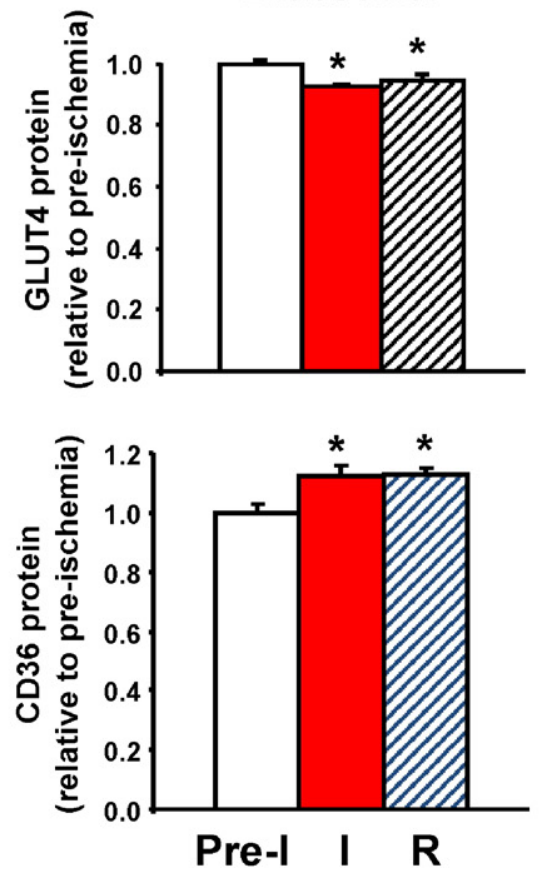

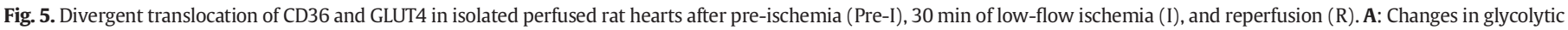

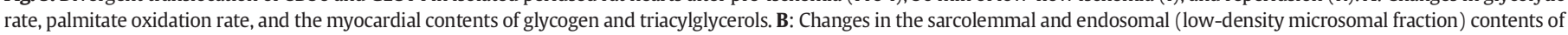
GLUT4 and CD36. Values are given as mean \pm SEM for $n=5$ per group, and were considered significant at $P<0.05$, ${ }^{*}$ versus pre-ischemia; $\dagger$ versus ischemia. Data obtained from [64].

\section{CD36 as target for metabolic modulation}

The key role of sarcolemmal CD36 in the (early) metabolic remodeling in cardiac disease makes this membrane protein an attractive therapeutic target, for instance to prevent and/or treat cardiac insulin resistance and diabetes-related contractile dysfunction. Theoretically, targeting CD36mediated fatty acid uptake could be achieved either by inhibiting the functioning of CD36 at the sarcolemma, or by interfering with the subcellular recycling of CD36 aimed at limiting its presence at the sarcolemma. Both approaches have been applied successfully.

Antibody inhibition of sarcolemmal CD36 was applied in a study with isolated rat cardiomyocytes cultured in a medium with excess palmitate, a condition that is known to elicit insulin resistance and reduce contractile function [75]. Chronic overexposure to excess lipids resulted in a markedly elevated sarcolemmal CD36 content, concomitantly with increased cellular fatty acid uptake and triacylglycerol accumulation. 


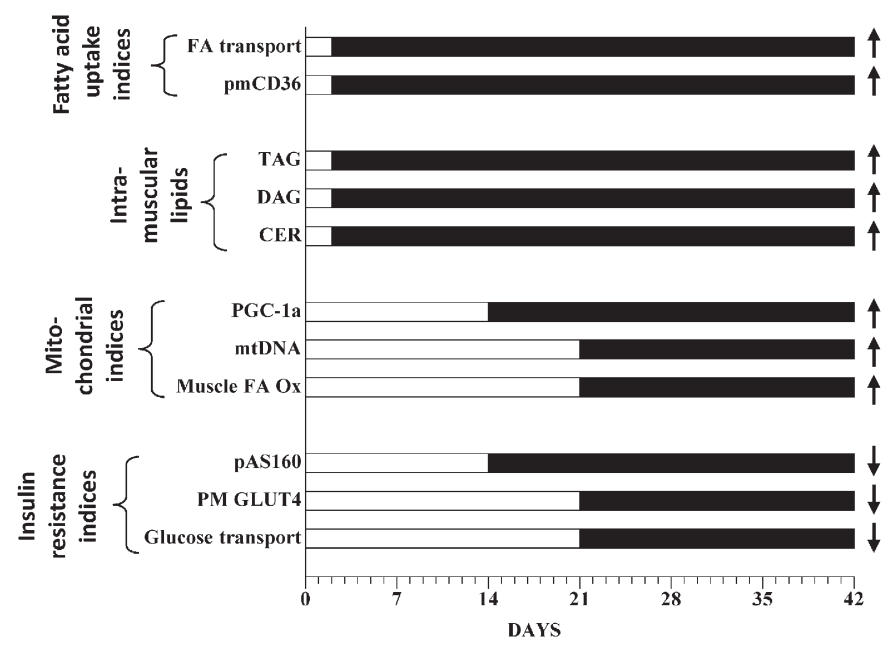

Fig. 6. Time course of changes induced by a high fat diet $(60 \%$ energy from fat, when compared to $10 \%$ ) in selected variables of fatty acid transport and metabolism, mitochondrial biogenesis and insulin sensitivity in rat oxidative skeletal muscle. White bars, no difference between chow- and fat-fed animals; black bars, onset and continuation of increases (upwards arrow) or decreases (downwards arrow) in high fat-fed animals. FA, fatty acid; CER, ceramide; DAG, diacylglycerol; Ox, oxidation; SL, sarcolemmal; TAG, triacylglycerol. Reproduced from [74], with permission.

Lipid oversupply also impaired contractile function (Fig. 7). While insulin was able to stimulate fatty acid uptake in control cells, cardiomyocytes cultured in high-palmitate medium did not respond to insulin, reflecting the induction of insulin resistance. Glucose uptake was affected in a similar manner (data not shown). Using anti-CD36 antibodies to inhibit fatty acid uptake, both lipid accumulation, loss of insulin sensitivity, and impairment of contractile function were prevented (Fig. 7), thus identifying CD36 as a target to combat lipid-induced cardiomyopathy [76].

Modulation of the subcellular cycling of substrate transporters also has been shown to be effective in the prevention of a substrate switch. Thus, overexpression of the trafficking protein VAMP3 in HL-1 atrial cardiomyocytes cultured in a lipotoxic medium prevented the lipidinduced increase in sarcolemmal CD36 and accompanying myocellular lipid accumulation (Fig. 8) [77]. Concomitantly, GLUT4 translocation in these VAMP3-overexpressing cardiomyocytes remained responsive to insulin [77], indicating that targeting a single protein from the trafficking machinery already may have a marked effect on cardiomyocyte substrate selection.

The impact of targeting CD36 on substrate handling, metabolic remodeling and changes in contractile function is also evident from the many studies on CD36 knock-out animals. As mentioned above, CD36 ablation was observed to rescue cardiac lipid accumulation and contractile dysfunction in mice with a cardiac-specific overexpression of PPAR $\alpha$ [73]. Both whole-body and cardiomyocyte-specific ablation of CD36 were found to reduce cardiac fatty acid uptake and oxidation, which was compensated by enhanced glucose oxidation, and markedly improved functional recovery following ischemia/reperfusion $[78,79]$. While the increased cardiac CD36 content in middle-aged mice, when compared to young mice, is associated with a higher sensitivity to developing high fat diet-induced cardiac hypertrophy, this difference between middle-aged and young mice is disappeared in CD36 null animals [80]. The absence of CD36 in mice also was reported to protect against cardiac dysfunction elicited by a combination of mechanical stress (pressure overload) and dietary stress (Western-type diet) [81]. Finally, cardiospecific CD36 suppression by lentivirus-mediated RNA interference was found to prevent cardiac hypertrophy and systolic dysfunction in high fat diet-induced obese mice [82].

\section{Concluding remarks}

Myocardial fatty acid uptake is largely regulated by the membrane protein CD36, especially through its continuous cycling from intracellular stores (endosomes) to the sarcolemma which is triggered by insulin and by myocyte contractions. CD36 thus serves a pivotal role in governing myocardial fatty acid utilization and, together with GLUT4, in determining substrate preference (fatty acids versus glucose, respectively). Proper functioning of CD36 appears of central importance to maintain metabolic homeostasis, and derangements therein (either towards inhibition or towards upregulation) will likely result in pathology.

Lowering the sarcolemmal presence of CD36 or inhibiting its functioning at the sarcolemma was shown in various model systems to decrease the rate of myocardial fatty acid uptake and prevent excessive fatty acid uptake seen in lipotoxic conditions such as obesity and high

\section{Palmitate uptake}

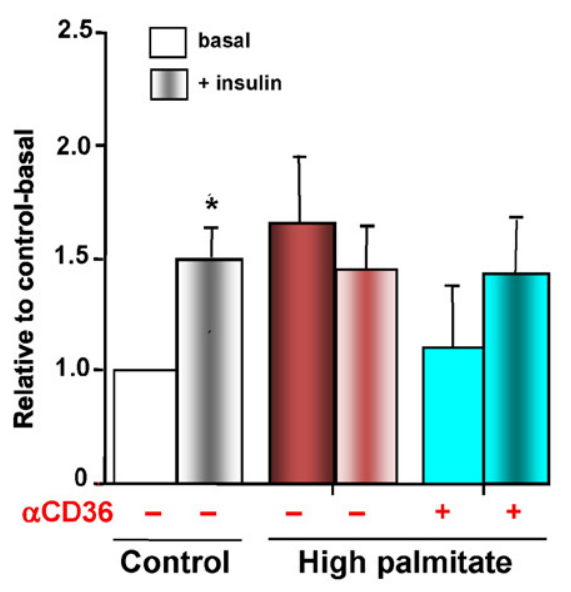

Triacylglycerol content

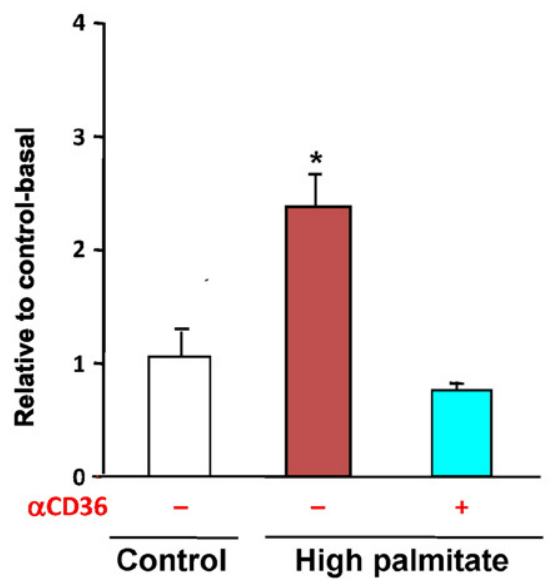

Sarcomere shortening

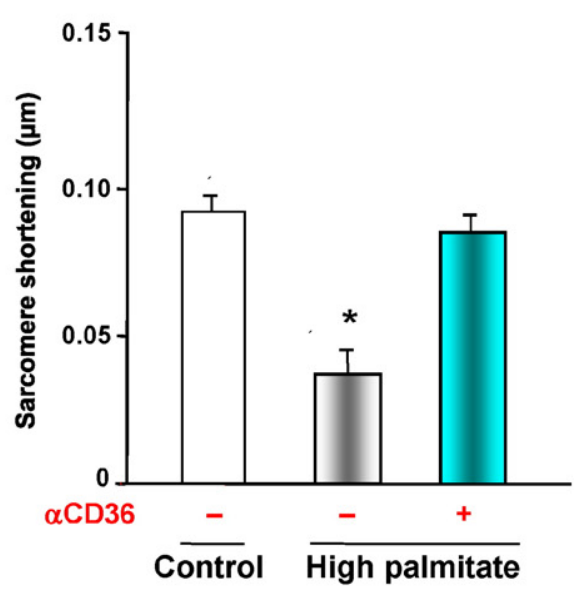

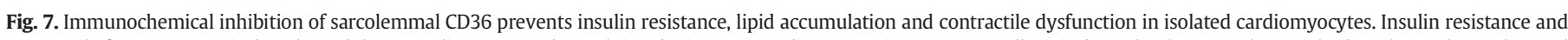

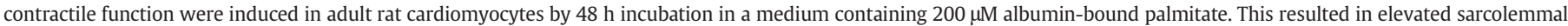

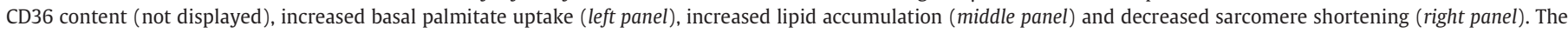

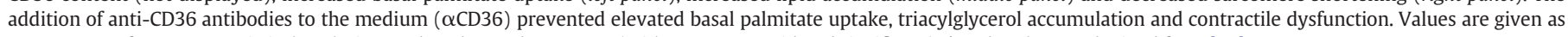
mean \pm SEM for $n=5$. Statistical analysis was done by Student's $t$ test (with $P<0.05$ considered significant): * vs. basal. Data obtained from [76]. 
Sarcolemmal CD36 content

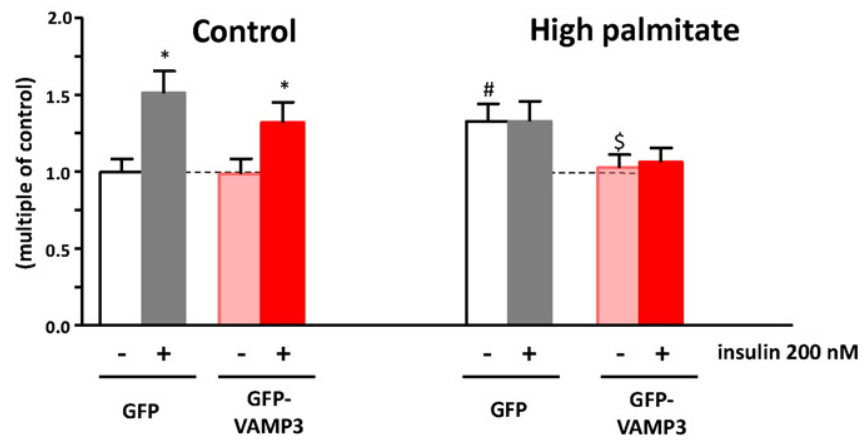

Triacylglycerol content

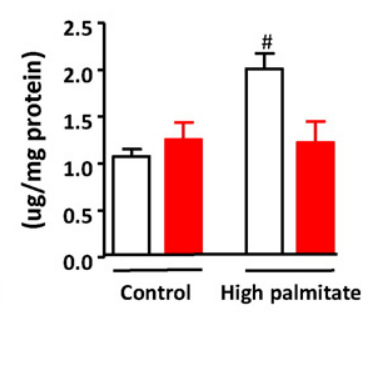

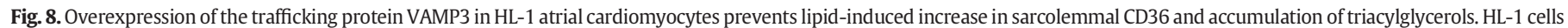

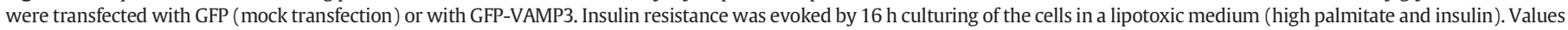

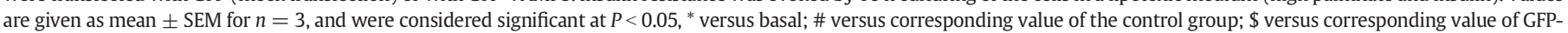
group. Data obtained from [77].

fat feeding. As a result, selective targeting of CD36, i.e., independent of changes in subcellular GLUT4 recycling, may become a suitable therapeutic intervention to restore abnormalities in the matching of myocellular fatty acid uptake to fatty acid oxidation, as seen for instance during lipid overload. Compounds need to be developed that would specifically inhibit sarcolemmal CD36 or would specifically target selected members of the trafficking proteins involved in CD36 recycling. Sulfo- $N$-succinimidyl-esters of long-chain fatty acids effectively inhibit sarcolemmal CD36 but, unfortunately, are not useful in vivo because of their chemical instability when in aqueous media [83]. Other acclaimed CD36-blocking compounds, e.g., hexarelin and EP80317, have been found unsuccessful to inhibit cardiac fatty acid uptake [76]. Agents affecting specific constituents of the cellular trafficking machinery have to our knowledge not yet been described. Alternatively, selected activation of signaling proteins upstream of the trafficking proteins would be a theoretical option.

Apart from these already feasible intervention approaches it is to be expected that additional therapeutic options will emerge once we obtain more mechanistic insight into the structure and functioning of CD36. For instance, the role of the ten glycosylation sites of CD36 remains underexplored, although recently evidence was reported for the importance of $\mathrm{O}$-linked- $\beta$ - $N$-acetylglucosamine for the membrane recruitment of CD36 and its role in fatty acid uptake [84]. In addition, CD36 has two extracellular phosphorylation sites for which the significance still is unclear. Moreover, as shown in liver, CD36 can be monoubiquitinated by Parkin (an E3 ubiquitin ligase) which stabilizes the protein by altering its turnover rate and concomitantly augments hepatic fatty acid uptake and hepatocellular lipid content [85]. Finally, CD36 is hypothesized to function in specific regions of the sarcolemma, e.g., microdomains like so-called lipid rafts, and caveolae, thereby perhaps interacting with specific membrane lipid species or with selected partner proteins like FABPpm or other membrane-associated or soluble proteins. As a result, the functioning of CD36 as a regulator of sarcolemmal fatty acid transport most likely may also be modulated by other approaches than described in this review.

\section{Conflict of interest}

Please note that there is no coinflict of interest.

\section{Transparency document}

The Transparency document associated with this article can be found, in online version.

\section{Acknowledgements}

Part of this work was supported by Diabetes UK funding (grant number $11 / 0004175$ to $\mathrm{LH}$ ). MN is the recipient of a VENI-Innovational Research Grant from the Netherlands Organization of Scientific Research (NWO-ZonMw Grant no. 916.14.050). AB was the Canada Research Chair (Tier I) in Metabolism and Health.

\section{References}

[1] R.J. Bing, A. Siegel, I. Ungar, M. Gilbert, Metabolism of the human heart II. Studies on fat, ketone and amino acid metabolism, Am. J. Med. 16 (1954) 504-515.

[2] W.C. Stanley, F.A. Recchia, G.D. Lopaschuk, Myocardial substrate metabolism in the normal and failing heart, Physiol. Rev. 85 (2005) 1093-1129.

[3] R.H. Unger, Lipotoxic diseases, Annu. Rev. Med. 53 (2002) 319-336.

[4] A.R. Wende, E.D. Abel, Lipotoxicity in the heart, Biochim. Biophys. Acta 1801 (2010) 311-319.

[5] F.G. Schaap, B. Binas, H. Danneberg, G.J. van der Vusse, J.F.C. Glatz, Impaired long-chain fatty acid utilization by cardiac myocytes isolated from mice lacking the heart-type fatty acid-binding protein gene, Circ. Res. 85 (1999) 329-337.

[6] H. Vorum, R. Brodersen, U. Kragh-Hansen, A.O. Pedersen, Solubility of long-chain fatty acids in phosphate buffer at pH 7.4, Biochim. Biophys. Acta 1126 (1992) 135-142.

[7] R.V. Richieri, A.M. Kleinfeld, Unbound free fatty acid levels in human serum, J. Lipid Res. 36 (1995) 229-240.

[8] M.M. Vork, J.F.C. Glatz, G.J. van der Vusse, On the mechanisms of long chain fatty acid transport in cardiomyocytes as facilitated by cytoplasmic fatty acid-binding protein, J. Theor. Biol. 160 (1993) 207-222.

[9] J.F.C. Glatz, J.J.F.P. Luiken, F.A. van Nieuwenhoven, G.J. van der Vusse, Molecular mechanism of cellular uptake and intracellular translocation of fatty acids, Prostaglandins Leukot. Essent. Fat. Acids 57 (1997) 3-9.

[10] A. Bonen, A. Chabowksi, J.J.F.P. Luiken, J.F.C. Glatz, Mechanisms and regulation of protein-mediated cellular fatty acid uptake: molecular, biochemical and physiological evidence, Physiology 22 (2007) 15-28.

[11] J.F.C. Glatz, J.J.F.P. Luiken, A. Bonen, Membrane fatty acid transporters as regulators of lipid metabolism: implications for metabolic disease, Physiol. Rev. 90 (2010) 367-417.

[12] J.F.C. Glatz, J.J.F.P. Luiken, Control of myocardial fatty acid uptake, in: G.D. Lopaschuk, N.S. Dhalla (Eds.), Cardiac Energy Metabolism in Health and Disease, Advances in Biochemistry in Health and Disease, 11, Springer Publishers 2014, pp. 49-67.

[13] F. Kamp, D. Zakim, F. Zhang, N. Noy, J.A. Hamilton, Fatty acid flip-flop in phospholipid bilayers is extremely fast, Biochemistry 34 (1995) 11928-11937.

[14] F. Zhang, F. Kamp, J.A. Hamilton, Dissociation of long and very long fatty acids from phospholipid bilayers, Biochemistry 35 (1996) 16055-16060.

[15] J.A. Hamilton, New insights into the roles of proteins and lipids in membrane transport of fatty acids, Prostaglandins Leukot. Essent. Fat. Acids 77 (2007) 355-361.

[16] V.L. Spitsberg, E. Matitashvili, R.C. Gorewit, Association and coexpression of fatty-acidbinding protein and glycoprotein CD36 in the bovine mammary gland, Eur. J. Biochem. 230 (1995) 872-878.

[17] N.A. Abumrad, M.R. El-Maghrabi, E.-Z. Amri, E. Lopez, P. Grimaldi, Cloning of a rat adipocyte membrane protein implicated in binding or transport of long chain fatty acids that is induced during preadipocyte differentiation. Homol- ogy with human CD36, J. Biol. Chem. 268 (1993) (1993).

[18] W. Stremmel, Fatty acid uptake by isolated heart myocytes represents a carriermediated transport process, J. Clin. Invest. 81 (1988) 844-852.

[19] J.E. Schaffer, H.F. Lodish, Expression cloning and characterization of a novel adipocyte long chain fatty acid transport protein, Cell 79 (1994) 427-436. 
[20] M. Kazantzis, A. Stahl, Fatty acid transport proteins, implications in physiology and diseases, Biochim. Biophys. Acta 1821 (2012) 852-857.

[21] A. Chabowski, J. Górski, J.J.F.P. Luiken, J.F.C. Glatz, A. Bonen, Evidence for concerted action of FAT/CD36 and FABPpm to increase fatty acid transport across the plasma membrane, Prostaglandins Leukot. Essent. Fat. Acids 77 (2007) 345-353.

[22] D.D.J. Habets, W.A. Coumans, P.J. Voshol, M.A. den Boer, M. Febbraio, A. Bonen, J.F.C. Glatz, J.J.F.P. Luiken, AMPK-mediated increase in myocardial long-chain fatty acid uptake critically depends on sarcolemmal CD36, Biochem. Biophys. Res. Commun. 355 (2007) 204-210.

[23] J.J.F.P. Luiken, F.A. van Nieuwenhoven, G. America, G.J. van der Vusse, J.F.C. Glatz, Uptake and metabolism of palmitate by isolated cardiac myocytes from adult rats: Involvement of sarcolemmal proteins, J. Lipid Res. 38 (1997) 745-758.

[24] J.J.F.P. Luiken, L.P. Turcotte, A. Bonen, Protein-mediated palmitate uptake and expression of fatty acid transport proteins in heart giant vesicles, J. Lipid Res. 40 (1999) 1007-1016.

[25] M. Febbraio, R.L. Silverstein, CD36: implications in cardiovascular disease, Int. J. Biochem. Cell Biol. 39 (2007) 2012-2030.

[26] M.Y. Pepino, O. Kuda, D. Samovski, N.A. Abumrad, Structure-function of CD36 and importance of fatty acid signal transduction in fat metabolism, Annu. Rev. Nutr. 34 (2014) 281-303.

[27] Z. Tahrda, A. Ibrahimi, Insight into the mechanisms of lipids binding and uptake by CD36 receptor, Bioinformation 11 (2015) 302-306.

[28] S.J. Hoosdally, E.J. Andress, C. Wooding, C.A. Martin, K.J. Linton, The human scavenger receptor CD36: glycosylation status and its role in trafficking and function, J. Biol. Chem. 284 (2009) 16277-16288.

[29] N. Tao, S.J. Wagner, D.M. Lublin, CD36 is palmitolylated on both N- and C-terminal cytoplasmic tails, J. Biol. Chem. 271 (1996) 22315-22320.

[30] R.L. Silverstein, M. Febbraio, CD36, a scavenger receptor involved in immunity, metabolism, angiogenesis, and behavior, Sci. Signal. 2 (2009) re3.

[31] P. Degrace-Passilly, P. Besnard, CD36 and taste of fat, Curr. Opin. Clin. Nutr. Metab. Care 15 (2012) 107-111.

[32] D. Neculai, M. Schwake, M. Ravichandran, F. Zunke, R.F. Collins, J. Peters, M. Neculai, J. Plump, P. Loppnau, J.C. Pizarro, A. Seitova, W.S. Trimble, P. Saftig, S. Grinstein, S. Dhe-Paganon, Structure of LMIP-2 provides functional insights with implications for SR-B1 and CD36, Nature 504 (2013) 172-176.

[33] A. Bonen, J.J.F.P. Luiken, Y. Arumugam, J.F.C. Glatz, N.N. Tandon, Acute regulation of fatty acid uptake involves the cellular redistribution of fatty acid translocase, J. Biol. Chem. 275 (2000) 14501-14508.

[34] J.J.F.P. Luiken, S.L.M. Coort, J. Willems, W.A. Coumans, A. Bonen, G.J. van der Vusse, J.F.C. Glatz, Contraction-induced fatty acid translocase/CD36 translocation in rat cardiac myocytes is mediated through AMP-activated protein kinase signaling, Diabetes 52 (2003) 1627-1634.

[35] A. Bonen, X.-X. Han, D.D.J. Habets, M. Febbraio, J.F.C. Glatz, J.J.F.P. Luiken, A null mutation in skeletal muscle FAT/CD36 reveals its essential role in insulin-, and AICAR-stimulated fatty acid metabolism, Am. J. Physiol. Endocrinol. Metab. 292 (2007) E1740-E1749.

[36] S.S. Jain, A. Chabowski, L.A. Snook, R.W. Schwenk, J.F.C. Glatz, J.J.F.P. Luiken, A. Bonen, Additive effects of insulin and muscle contraction on fatty acid transport and fatty acid transporters, FAT/CD36, FABPpm, FATP1, 4 and 6, FEBS Lett. 583 (2009) 2294-2300.

[37] A. Chabowski, S.L.M. Coort, J. Calles-Escandon, N.N. Tandon, J.F.C. Glatz, J.J.F.P. Luiken, A. Bonen, The subcellular compartmentation of fatty acid transporters is regulated differently by insulin and by AICAR, FEBS Lett. 579 (2005) 2428-2432.

[38] A. Chabowski, S.L.M. Coort, J. Calles-Escandon, N.N. Tandon, J.F.C. Glatz, J.J.F.P. Luiken, A. Bonen, Insulin stimulates fatty acid transport by regulating expression of FAT/ CD36 but not FABPpm, Am. J. Physiol. Endocrinol. Metab. 287 (2004) E781-E789.

[39] J. Kerner, C. Hoppel, Fatty acid import into mitochondria, Biochim. Biophys. Acta 1486 (2000) 1-17.

[40] J.-P. Bonnefont, F. Djouadi, C. Prip-Buus, S. Gobin, A. Munnich, J. Bastin, Carnitine palmitoyltransferases 1 and 2: biochemical, molecular and medical aspects, Mol. Asp. Med. 25 (2004) 495-520.

[41] M.M. Awan, E.D. Saggerson, Malonyl-CoA metabolism in cardiac myocytes and its relevance to the control of fatty acid oxidation, Biochem. J. 295 (1993) 61-66.

[42] M. Saddik, J. Gamble, L.A. Witters, G.D. Lopaschuk, Acetyl-CoA carboxylase regulation of fatty acid oxidation in the heart, J. Biol. Chem. 268 (1993) 25836-25845.

[43] S. Eaton, Control of mitochondrial beta-oxidation flux, Prog. Lipid Res. 41 (2002) 197-239.

[44] A.N. Carley, D.L. Severson, What are the biochemical mechanisms responsible for enhanced fatty acid utilization by perfused hearts from type 2 diabetic $\mathrm{db} / \mathrm{db}$ mice? Cardiovasc. Drugs Ther. 22 (2008) 83-89.

[45] A.N. Carley, L.L. Atkinson, A. Bonen, M.E. Harper, S. Kunnathu, G.D. Lopaschuk, D.L. Severson, Mechanisms responsible for enhanced fatty acid utilization by perfused hearts from type 2 diabetic $d b / d b$ mice, Arch. Physiol. Biochem. 113 (2007) 65-75.

[46] J.J.F.P. Luiken, H.E. Niessen, S.L.M. Coort, N.T.H. Hoebers, W.A. Coumans, R.W. Schwenk, A. Bonen, J.F.C. Glatz, Etomoxir-induced partial CPT-I inhibition in vivo does not alter cardiac long-chain fatty acid uptake and oxidation rates, Biochem. J. 419 (2009) 447-455.

[47] D. Leto, A.R. Saltiel, Regulation of glucose transport by insulin: traffic control of GLUT4, Nat. Rev. Mol. Cell Biol. 13 (2012) 383-396.

[48] A. Klip, Y. Sun, T.T. Chiu, K.P. Foley, Signal transduction meets vesicle traffic: the software and hardware of GLUT4 translocation, Am. J. Physiol. Cell Physiol. 306 (2014) C879-C886.

[49] M. Larance, G. Ramm, J. Stöckli, E.M. van Dam, S. Winata, V. Wasinger, F. Simpson, M. Graham, J.R. Junutula, M. Gulhaus, D.E. James, Characterization of the role of the Rab GTPase-activating protein AS160 in insulin-regulated GLUT4 trafficking, J. Biol. Chem. 280 (2005) 37803-37813.
[50] H. Müller, K. Deckers, J. Eckel, The fatty acid translocase (FAT)/CD36 and the glucose transporter GLUT4 are localized in different cellular compartments in rat cardiac muscle, Biochem. Biophys. Res. Commun. 293 (2002) 665-669.

[51] H.T. McMahon, I.G. Mills, COP and clathrin-coated vesicle budding: different pathways, common approaches, Curr. Opin. Cell Biol. 16 (2004) 379-391.

[52] L.K.M. Steinbusch, W. Wijnen, R.W. Schwenk, W.A. Coumans, N.T.H. Hoebers, D.M. Ouwens, M. Diamant, A. Bonen, J.F.C. Glatz, J.J.F.P. Luiken, Differential regulation of cardiac glucose and fatty acid uptake by endosomal $\mathrm{pH}$ and actin filaments, Am. J. Physiol. Cell Physiol. 298 (2010) C1549-C1559.

[53] A.S. Augustus, J. Buchanan, S. Addya, G. Rengo, R.G. Pestell, P. Fortina, W.J. Koch, A. Bensadoun, E.D. Abel, M.P. Lisanti, Substrate uptake and metabolism are preserved in hypertrophic caveolin-3 knockout hearts, Am. J. Physiol. Heart Circ. Physiol. 295 (2008) H657-H666.

[54] T. Satoh, Molecular mechanisms for the regulation of insulin-stimulated glucose uptake by small guanosine triphosphatases in skeletal muscle and adipocytes, Int. J. Mol. Sci. 15 (2014) 18677-18692.

[55] D. Samovski, X. Su, Y. Xu, N.A. Abumrad, P.D. Stahl, Insulin and AMPK regulate FA translocase/CD36 plasma membrane recruitment in cardiomyocytes via Rab GAP AS160 and Rab8a RAB GTPase, J. Lipid Res. 53 (2012) 709-717.

[56] R.W. Schwenk, J.J.F.P. Luiken, J. Eckel, FIP2 and Rip11 specify Rab11a-mediated cellular distribution of GLUT4 and FAT/CD36 in H9c2-hIR cells, Biochem. Biophys Res. Commun. 363 (2007) 119-125.

[57] M. Kawanishi, Y. Tamori, H. Okazawa, S. Araki, H. Shinoda, M. Kasuga, Role of SNAP23 in insulin-induced translcoation of GLUT4 in 3 T3-L1 adipocytes. Mediation of complex formation between syntaxin 4 and VAMP2, J. Biol. Chem. 275 (2000) 8240-8247.

[58] R.W. Schwenk, E. Dirkx, W.A. Coumans, A. Bonen, A. Klip, J.F.C. Glatz, J.J.F.P. Luiken, Requirement for distinct vesicle-associated membrane proteins in insulin- and AMP-activated protein kinase (AMPK)-induced translocation of GLUT4 and CD36 in cultured cardiomyocytes, Diabetologia 53 (2010) 2209-2219.

[59] L.K.M. Steinbusch, R.W. Schwenk, D.M. Ouwens, M. Diamant, J.F.C. Glatz, J.J.F.P. Luiken, Subcellular trafficking of the substrate transporters GLUT4 and CD36 in cardiomyocytes, Cell. Mol. Life Sci. 68 (2011) 2525-2538.

[60] I. Dulubova, S. Sugita, S. Hill, M. Hosaka, I. Fernandez, T.C. Südhof, J. Rizo, A conformational switch in syntaxin during exocytosis: role of munc18, EMBO J. 18 (1999) 4372-4382.

[61] D.D.J. Habets, C. Thurmond, W.A. Coumans, A. Bonen, J.F.C. Glatz, J.J.F.P. Luiken, Munc18c is not rate-limiting for glucose and long-chain fatty acid uptake in the heart, Mol. Cell. Biochem. 322 (2009) 81-86.

[62] J.S. Jaswal, W. Keung, W. Wang, J.R. Ussher, G.D. Lopaschuk, Targeting fatty acid and carbohydrate oxidation - a novel therapeutic intervention in the ischemic and failing heart, Biochim. Biophys. Acta 1813 (2011) 1333-1350.

[63] L.H. Opie, M.N. Sack, Metabolic plasticity and the promotion of cardiac protection in ischemia and ischemic preconditioning, J. Mol. Cell. Cardiol. 34 (2002) 1077-1089.

[64] L.C. Heather, K.M. Pates, H.J. Atherton, M.A. Cole, D.R. Ball, R.D. Evans, J.F.C. Glatz, J.J.F.P. Luiken, J.L. Griffin, K. Clarke, Differential translocation of the fatty acid transporter, FAT/CD36, and the glucose transporter, GLUT4, coordinates changes in cardiac substrate metabolism during ischemia and reperfusion, Circ. Heart Fail. 6 (2013) 1058-1066.

[65] L.C. Heather, M.A. Cole, C.A. Lygate, R.D. Evans, D.J. Stuckey, A.J. Murray, S. Neubauer K. Clarke, Fatty acid transporter levels and palmitate oxidation rate correlate with ejection fraction in the infarcted rat heart, Cardiovasc. Res. 72 (2006) 430-437.

[66] L.C. Heather, N.J. Howell, Y. Emmanuel, M.A. Cole, M.P. Frenneaux, D. Pagano, K. Clarke, Changes in cardiac substrate transporters and metabolic proteins mirror the metabolic shift in patients with aortic stenosis, PLoS One 6 (2011) e26326.

[67] G. Boden, Role of fatty acids in the pathogenesis of insulin resistance and NIDDM Diabetes 46 (1997) 3-10.

[68] J.K. Kim, J.J. Fillmore, Y. Chen, C. Yu, I.K. Moore, M. Pypaert, E.P. Lutz, Y. Kako, W. Velez-Carrasco, I.J. Goldberg, J.L. Bresow, G.I. Shulman, Tissue-specific overexpression of lipoprotein lipase causes tissue-specific insulin resistance, Proc. Natl. Acad. Sci. U. S. A. 98 (2001) 7522-7527.

[69] D.B. Savage, K.F. Petersen, G.I. Shulman, Disordered lipid metabolism and the pathogenesis of insulin resistance, Physiol. Rev. 87 (2007) 507-520.

[70] S.L.M. Coort, D.M. Hasselbaink, D.P.Y. Koonen, J. Willems, W.A. Coumans, A Chabowski, G.J. van der Vusse, A. Bonen, J.F.C. Glatz, J.J.F.P. Luiken, Enhanced sarcolemmal FAT/CD36 content and triacylglycerol storage in cardiac myocytes from obese Zucker rats, Diabetes 53 (2004) (1655-1663).

[71] D.M. Ouwens, M. Diamant, M. Fodor, D.D. Habets, M.M.A.L. Pelsers, M. El Hanaoui, Z.C. Dang, C.E. van den Brom, R. Vlasblom, A. Rietdijk, C. Boer, S.L.M. Coort, J.F.C. Glatz, J.J.F.P. Luiken, Cardiac contractile dysfunction in insulin-resistant rats fed a high fat diet is associated with elevated CD36- mediated fatty acid uptake and esterification, Diabetologia 50 (2007) 1938-1948.

[72] C. Aguer, J. Mercier, C.Y. Man, L. Metz, S. Bordenave, K. Lambert, E. Jean, L. Lantier, L Bounoua, J.F. Brun, E. Raynaud de Mauverger, F. Andreelli, M. Foretz, M. Kitzmann, Intramyocellular lipid accumulation is associated with permanent relocation ex vivo and in vitro of fatty acid translocase (FAT)/CD36 in obese patients, Diabetologia 53 (2010) 1151-1163.

[73] J. Yang, N. Sambandam, X. Han, R.W. Gross, M. Courtois, A. Kovacs, M. Febbraio, B.N. Finck, D.P. Kelly, CD36 deficiency rescues lipotoxic cardiomyopathy, Circ. Res. 100 (2007) 1208-1217.

[74] A. Bonen, S.S. Jain, L.A. Snook, X.-X. Han, Y. Yoshida, K.H. Buddo, J.S. Lally, E.D. Pask, S Paglialunga, M.S. Beaudoin, J.F.C. Glatz, J.J.F.P. Luiken, E. Harasim, D.C. Wright, A. Chabowski, G.P. Holloway, Extremely rapid increase in fatty acid transport and intramyocellular lipid accumulation but markedly delayed insulin resistance after high fat feeding in rats, Diabetologia 58 (2015) 2381-2391. 
[75] L. Bertrand, A. Ginion, C. Beauloye, A.D. Hebert, B. Guigas, L. Hue, J.L. Vanoverschelde, AMPK activation restores the stimulation of glucose uptake in an in vitro model of insulin-resistant cardiomyocytes via the activation of protein kinase B, Am. J. Physiol. Heart Circ. Physiol. 291 (2006) H239-H250.

[76] Y. Angin, L.K.M. Steinbusch, P.J. Simons, S. Greulich, N.T.H. Hoebers, K. Douma, M.A.M.J. van Zandvoort, W.A. Coumans, W. Wijnen, M. Diamant, D.M. Ouwens, J.F.C. Glatz, J.J.F.P. Luiken, CD36 inhibition prevents lipid accumulation and contractile dysfunction in rat cardiomyocytes, Biochem. J. 448 (2012) 43-53.

[77] R.W. Schwenk, Y. Angin, L.K.M. Steinbusch, E. Dirkx, N. Hoebers, W.A. Coumans, A Bonen, J.L. Broers, G.J.J.M. van Eys, J.F.C. Glatz, J.J.F.P. Luiken, Overexpression of vesicle-associated membrane protein (VAMP) 3, but not VAMP2, protects glucose transporter (GLUT) 4 protein translocation in an in vitro model of cardiac insulin resistance, J. Biol. Chem. 287 (2012) 37530-37539.

[78] M. Kuang, M. Febbraio, C. Wagg, G.D. Lopaschuk, J.R.B. Dyck, Fatty acid translocase/ CD36 deficiency does not energetically or functionally compromise hearts before or after ischemia, Circulation 109 (2004) 1550-1557.

[79] J. Nagendran, T. Pulinilkunnil, P.C. Kienesberger, M.M. Sung, D. Fung, M. Febbraio J.R.B. Dyck, Cardiomyocyte-specific ablation of CD36 improves post-ischemic functional recovery, J. Mol. Cell. Cardiol. 63 (2013) 180-188.

[80] M.M. Sung, D.P.Y. Koonen, C.-L.M. Soltys, R.L. Jacobs, M. Febbraio, J.R.B. Dyck, Increased CD36 expression in middle-aged mice contributes to obesity-related cardiac hypertrophy in the absence of cardiac dysfunction, J. Mol. Med. 89 (2011) 459-469.
[81] L.K.M. Steinbusch, J.J.F.P. Luiken, R. Vlasblom, A. Chabowski, N.T.H. Hoebers, W.A. Coumans, I.O.C.M. Vroegrijk, P.J. Voshol, D.M. Ouwens, J.F.C. Glatz, M. Diamant, Absence of fatty acid transporter CD36 protects against Western-type diet-related cardiac dysfunction following pressure overload in mice, Am. J. Physiol. Endocrinol. Metab. 301 (2011) E618-E628.

[82] Y. Zhang, M. Bao, M. Dai, X. Wang, W. He, T. Tan, D. Lin, W. Wang, Y. Wen, R. Zhang, Cardiospecific CD36 suppression by lentivirus-mediated RNA interference prevents cardiac hypertrophy and systolic dysfunction in high-fat-diet induced obese mice, Cardiovasc. Diabetol. 14 (2015) 69.

[83] S.L.M. Coort, J. Willems, W.A. Coumans, G.J. van der Vusse, A. Bonen, J.F.C. Glatz, J.J.F.P. Luiken, Sulfo- $N$-succinimidyl esters of long chain fatty acids specifically inhibit fatty acid translocase (FAT/CD36)-mediated cellular fatty acid uptake, Mol. Cell. Biochem. 239 (2002) 213-219.

[84] B. Lauzier, C. Merlen, F. Vaillant, J. McDuff, B. Bouchard, P.C. Beguin, V.W. Dolinsky, S. Foisy, L.R. Villeneuve, F. Labarthe, J.R. Dyck, B.G. Allen, G. Charron, C. Des Rosiers, Post-translocational modifications, a key process in CD36 function: lessons from the spontaneously hypertensive rat heart, J. Mol. Cell. Cardiol. 51 (2011) 99-108.

[85] K.-Y. Kim, M.V. Stevens, M.H. Akter, S.E. Rusk, R.J. Huang, A. Cohen, A. Noguchi, D. Springer, A.V. Bocharov, T.L. Eggerman, D.-F. Suen, R.J. Youle, M. Amar, A.T. Remaley, M.N. Sack, Parkin is a lipid-responsive regulator of fat uptake in mice and mutant human cells, J. Clin. Invest. 121 (2011) 3701-3712. 